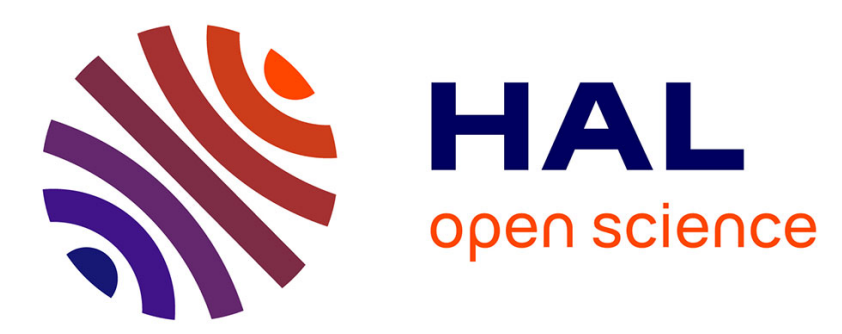

\title{
A Fast and reproducible method to quantify magnetic nanoparticle biodistribution
}

Lionel Maurizi, Usawadee Sakulkhu, Azza Gramoun, Jean-Paul Vallée, Heinrich Hofmann

\section{- To cite this version:}

Lionel Maurizi, Usawadee Sakulkhu, Azza Gramoun, Jean-Paul Vallée, Heinrich Hofmann. A Fast and reproducible method to quantify magnetic nanoparticle biodistribution. Analyst, 2014, 139 (5), pp.1184-1191. 10.1039/C3AN02153J . hal-02163403

\section{HAL Id: hal-02163403 https://hal.science/hal-02163403}

Submitted on 9 Mar 2021

HAL is a multi-disciplinary open access archive for the deposit and dissemination of scientific research documents, whether they are published or not. The documents may come from teaching and research institutions in France or abroad, or from public or private research centers.
L'archive ouverte pluridisciplinaire HAL, est destinée au dépôt et à la diffusion de documents scientifiques de niveau recherche, publiés ou non, émanant des établissements d'enseignement et de recherche français ou étrangers, des laboratoires publics ou privés. 


\title{
Fast and reproducible method to quantify magnetic nanoparticles biodistribution
}

\author{
Lionel Maurizi $^{1 *}$, Usawadee Sakulkhu ${ }^{1}$, Azza Gramoun $^{2}$, Jean-Paul Vallee $^{2}$, Heinrich Hofmann $^{1}$ \\ 1: Powder Technology Laboratory, Ecole Polytechnique Federale de Lausanne, CH-1015 Lausanne, Switzerland \\ 52: Department of Radiology, University of Geneva and Geneva University Hospital, 1211 Geneva 14, Switzerland \\ * Powder Technology Laboratory, Ecole Polytechnique Federale de Lausanne, CH-1015 Lausanne, Switzerland, lionelmaurizi@gmail.com
}

\section{Received (in $X X X, X X X)$ Xth $X X X X X X X X X 20 X X$, Accepted Xth $X X X X X X X X X 20 X X$ \\ DOI: $10.1039 / b 000000 x$}

\begin{abstract}
The quantification of nanoparticles, particularly superparamagnetic iron oxide nanoparticles 10 (SPION), both in vitro and in vivo has become highly important in recent years. Some methods, such as induced coupled plasma spectroscopy (ICP) and UV-visible chemical titration using Prussian blue (PB), already exist however they consist of the titration of the whole iron content. These standard methods need sample preparations leading to their destructions and long measurements time. In this study, we used magnetic susceptibility measurements (MSM) to titrate magnetic particles concentration and

15 biodistribution in the organs of rats. The advantages of MSM SPION quantification technique are presented and compared to widely used methods of iron oxide titration such as ICP and PB UV-visible titration. We have demonstrated that MSM is a simpler, faster (1 second per measurement), more reproducible and highly sensitive technique for SPION detection with minimal detection around $2 \mu \mathrm{g}_{\mathrm{Fe}} / \mathrm{mL}$ without being influenced by neither the SPION coating nor their surrounding environment. ${ }_{20}$ Moreover, MSM is a more robust method as it is not affected by endogenous iron facilitating the distinction of SPIONs (iron present as nanoparticles) from background iron in tissues. This advantage allows the decrease of control samples needed in biological studies. In conclusion, we have demonstrated that MSM is a standard method that can be easily setup to determine biodistribution of SPIONs regardless of their environment.
\end{abstract}

${ }_{25}$ Keywords: Induced Coupled Plasma Spectroscopy (ICP), Magnetic susceptibility measurements (MSM), Prussian Blue (PB), iron quantification, Superparamagnetic iron oxide nanoparticles (SPION), biodistribution.

\section{Introduction}

Superparamagnetic iron oxide nanoparticles (SPION) are 30 prepared from magnetite $\left(\mathrm{Fe}_{3} \mathrm{O}_{4}\right)$ or maghemite $\left(\gamma-\mathrm{Fe}_{2} \mathrm{O}_{3}\right)$ crystallites smaller than $15 \mathrm{~nm}$ which is responsible for their superparamagnetic behavior ${ }^{1}$. Because of this specific property, SPION have become important for various in vivo and in vitro biomedical applications such as imaging, magnetic separation, ${ }_{35}$ biosensing and therapy ${ }^{2,3}$. In order to be used in biomedical applications, SPION are usually stabilized in physiological media with biocompatible surface coating ${ }^{4-6}$. Accurate quantification of SPION is needed to determine their concentrations in different media and to assess their biodistribution and toxicity as well as 40 their targeted delivery.

Currently, several analytical techniques for SPION quantification exist. The most widely used are chemical methods such as Induced Coupled Plasma technique (ICP-MS: mass spectrometry or ICP-OES: optical emission spectrometry $)^{7-9}$. Other optical 45 methods also exist based on fluorescent detection which require fluorescently labelled SPION ${ }^{10,11}$. Additionaly, the analysis of coloured reactive chemicals such as Prussian Blue (PB) is used for SPION localization ${ }^{12}$ and for concentration measurements using UV-Visible analysis ${ }^{13,14}$.

so ICP-OES or PB techniques can quantify the iron content in samples and tissues but require a preliminary digestion of the SPION into its ionic forms $\left(\mathrm{Fe}^{\mathrm{II}}\right.$ and $\mathrm{Fe}^{\mathrm{III}}$ ) over a period of 24 hours to detect their concentration based on comparison to iron calibration curves ${ }^{14-17}$. The detection limit of ICP-OES is ${ }_{55}$ approximately $0.1 \mathrm{ppm}\left(0.1 \mu \mathrm{g}_{\mathrm{Fe}} / \mathrm{mL}\right)^{15}$ and at least $5 \mathrm{ppm}$ for the PB method ${ }^{14}$. However, even if they are commonly used, these methods are destructive because they need a dissolution step before the measurement. Moreover, they don't allow distinction between elemental iron and dissolved magnetic particles and ${ }_{60}$ endogenous iron found in the tissues and body fluids in the form of iron protein complexes, i.e. in liver transferrin, ferritin or hemoglobin $^{18,19}$.

SPION have specific superparamagnetic properties ${ }^{20}$ and can thus be detected in magnetic resonance imaging (MRI) or with 
magnetic resonance relaxometric methods ${ }^{21,22}$. Although MRI equipment is not available in many labs for routine measurements, a fast and easy method exists to quantify SPION using their magnetic susceptibilities. This technique is already 5 well established in geology and environmental analyses to detect one of the most ferromagnetic minerals in soil: the magnetite $\left(\mathrm{Fe}_{3} \mathrm{O}_{4}\right)^{23-25}$. Magnetic susceptibility measurements (MSM) do not need any preliminary modification of the samples and because they can be managed in environmental analysis, the 10 measuring time is very short (approximately 1s) and reproducible ${ }^{23}$. Some studies have suggested that MSM can is able to measure SPION biodistribution ${ }^{7,26,27}$ and cellular uptake $^{28,29}$. A study performed by Guo et al. ${ }^{30}$ proved that the minimum detection of MSM was $1.2 \mathrm{ppm}\left(1.2 \mu \mathrm{g}_{\mathrm{Fe}} / \mathrm{mL}\right)$ and that

15 this technique was only influenced by endogenous ferric iron at a concentration higher than $3000 \mathrm{ppm}\left(3000 \mu \mathrm{g}_{\mathrm{Fe}} / \mathrm{mL}\right)$.

In this report, a systematic study of magnetic susceptibility measurements was conducted to prove that MSM is a convenient and accurate way to quantify SPION (maghemite $\gamma-\mathrm{Fe}_{2} \mathrm{O}_{3}$ ) in 20 different media. To this end, Calibrations curves relating SPION magnetic susceptibilities and their concentrations were measured in water and foetal bovine serum to detect the influence of media on such measurements. The influence of coating was also studied through measurements of uncoated and polymer coated SPION.

${ }_{25}$ Quantification of SPION in water and sera and biodistribution in rat's organs were also performed. Furthermore, the effect of the state of the organ (either wet or dry) was examined. Finally, the minimal detection level of this technique was determined.

To evaluate the efficiency of MSM, their results were always 30 then compared to the results obtained from Prussian Blue (PB) and Induced Coupled Plasma (ICP) techniques.

Finally, we were able to prove that MSM is an accurate, quick and simple technique to detect SPION (iron present as nanoparticles) in several media without any influence of iron 35 background of biological samples.

\section{Materials and methods}

\section{Materials}

All chemicals were analytical reagent grade and were used without further purification. Ultrapure deionized water (Seralpur ${ }_{40}$ Delta UV/UF setting, $0.055 \mu \mathrm{S} / \mathrm{cm}$ ) was used in all synthesis and analysis steps. PVA-OH, Mowiol 3-85 with was supplied by courtesy of Kuraray. Amino-PVA (A-PVA): M12 was supplied by courtesy of Erkol. PVA-OH (10 wt $\%$ ) and A-PVA (2 wt $\%$ ) solutions were prepared by dissolving dry PVA in water and the 45 solutions were rapidly heating for 1 hour at $90^{\circ} \mathrm{C}$, cool down, filtered at $0.45 \mu \mathrm{m}$ with PTFE filter syringe and stored at $4^{\circ} \mathrm{C}$. MWCO 12-14 kDa cellulose membrane dialysis tubing was used for dialysis. The obtained ferrofluids were stored at $4^{\circ} \mathrm{C}$. Aqua regia solution was prepared by mixing 3 volumes of $\mathrm{HCl} 37 \%$ $50(12 \mathrm{M})$ and 1 volume of $\mathrm{HNO}_{3} 65 \%(\sim 15 \mathrm{M}) . \mathrm{HCl} 6 \mathrm{M}$ was produced by dilution of $\mathrm{HCl} 12 \mathrm{M}$ in distilled water (volume ratio 1:1). $\mathrm{HNO}_{3} 10 \mathrm{mM}$ solution was obtained by dissolution of $\mathrm{HNO}_{3}$ $15 \mathrm{M}$ in distilled water (volume ratio 1:1500). Potassium ferrocyanide $\left(\mathrm{K}_{4}^{+} \mathrm{Fe}^{2+}\left(\mathrm{CN}^{-}\right)_{6}\right)$ was provided from Sigma Aldrich. $552.5 \mathrm{~g}$ of $\mathrm{K}_{4}^{+} \mathrm{Fe}^{2+}\left(\mathrm{CN}^{-}\right)_{6}$ was dissolved in $50 \mathrm{~mL}$ of distilled water to obtain a $5 \%$ (weight/volume) ferrocyanide solution. Foetal bovine serum (FBS) was provided from Life Technologies.

\section{Experimental design}

\section{PVA surface modification of SPION}

${ }_{60}$ Naked SPION were synthesized following a known classical coprecipitation protocol $^{31,32}$. Surface modification of the SPION with PVA was done following a protocol described previously ${ }^{33}$. The PVA-SPION suspension at $\mathrm{pH}$ around 3 and at $6 \mathrm{mg}_{\mathrm{Fe}} / \mathrm{mL}$ was stored at least 1 week at $4^{\circ} \mathrm{C}$ before further use. The 65 crystallite's mean diameter was measured by counting 400 diameters on TEM pictures (CM 12 from Phillips). Hydrodynamic diameters (number weighted) such as Zeta potential at $\mathrm{pH} 7$ were measured with a Dynamic Light Scattering instrument (DLS: ZetaPals from Brookhaven). The amount of 70 PVA was measured by ThermoGravimetric Analysis (TGA/SDTA 851e from Mettler Toledo) from 25 to $800^{\circ} \mathrm{C}$.

\section{Serum}

Three times $1 \mathrm{~mL}$ of serum were used as control serum. Three times $992 \mu \mathrm{L}$ of serum were mixed with $8 \mu \mathrm{L}$ of PVA-SPION at $756 \mathrm{mg}_{\mathrm{Fe}} / \mathrm{mL}$ to obtained 3 suspensions at $50 \mu \mathrm{g}_{\mathrm{Fe}} / \mathrm{mL}$. Three times $984 \mu \mathrm{L}$ of serum were mixed with $16 \mu \mathrm{L}$ of PVA-SPION at $6 \mathrm{mg}_{\mathrm{Fe}} / \mathrm{mL}$ to obtained 3 suspensions at $100 \mu \mathrm{g}_{\mathrm{Fe}} / \mathrm{mL}$.

\section{Organs}

The $\mathrm{pH}$ of PVA-SPION suspension was adjusted to 7.4 with ${ }_{80} \mathrm{NaOH}(1 \mathrm{M})$ solution just before experiment. All experimental procedures received approval from the local animal care committees and were conducted in accordance with the guidelines of the Swiss Committee of Animal Experiments. Two months old female Lewis rats (approximately $200 \mathrm{~g}$, purchased 85 from Javier France) were anesthetized with 5\% isoflurane. 12 rats were divided into 2 groups according to the injected solutions: $150 \mathrm{mM} \mathrm{NaCl}$ (4 Control rat), and PVA-SPION (8 rats). $7 \mathrm{mg}$ iron of nanoparticle were injected through intravenous tail. 15 minutes after injection, the rats were sacrificed and livers and 90 spleens were sampled and stored at $-80^{\circ} \mathrm{C}$. The organs were then freeze-dried $\left(-50^{\circ} \mathrm{C}, 0.1 \mathrm{mbar}\right)$ for 24 hours. The dried samples were then weighted just after the freeze drying step. Livers (from 1.5 to $2.5 \mathrm{~g}$ ) were crushed into powder for further experiments and spleens (from 0.07 to $0.16 \mathrm{~g}$ ) were kept as such.

\section{${ }_{95}$ Methods}

\section{Analysis methods}

Prussian Blue measurements (PB) were done by colorimetric method using Potassium ferrocyanide $\left(\mathrm{K}_{4}^{+} \mathrm{Fe}^{2+}\left(\mathrm{CN}^{-}\right)_{6}\right)$ chemical which reacts with $\mathrm{Fe}^{3+}$ to give a blue product called Prussian Blue $100\left(4 \mathrm{Fe}^{3+}\left[\mathrm{Fe}^{\mathrm{II}}(\mathrm{CN})_{6}\right]_{3}+4 \mathrm{KCl}\right)$. By working in excess of potassium ferrocyanide compared to $\mathrm{Fe}^{3+}$, the $\mathrm{Fe}^{3+}$ is titrated by the blue colour absorbance measured with a Tecan Infinite 2000. All the solutions were analyzed in 96 wells plates ${ }^{34}$.

Induced Coupled Plasma Atomic Emission Spectroscopy 105 measurements (ICP-OES) were done using ICPE-9000 Shimadzu with $\mathrm{Fe}^{3+}$ calibration solution from Epond SA.

Magnetic susceptibility measurements (MSM) were performed on a Bartington MS3 magneto-susceptometer at 300K. 2 sensors were used during this study: MS2B dual frequency sensor for 10 $110 \mathrm{~mL}$ cells operated at low frequency $(0.465 \mathrm{kHz})$ and a magnetic field at $250 \mu \mathrm{T}$ and MS2G mono frequency sensor for around 1 $\mathrm{mL}$ cells operated at $(1.3 \mathrm{kHz})$. With the help of the two sensors, the magneto-susceptometer gives volume magnetic susceptibility 
values in standard units (SI) with a precision of $2 \cdot 10^{-6}$ SI calibrated per cell volume ${ }^{35}$. The bared values are different for MS2B and MS2G sensor because of the difference of frequency. Before every measurement, a control cell with the same media or 5 material without any SPION was measured and subtracted as background $^{24}$. The magneto-susceptometer MS3 with its 2 sensors is transportable with dimensions of around $300 \times 200 \times 150 \mathrm{~mm}$ and a weight of $2 \mathrm{~kg}$. This instrument can be piloted by any laptop or computer with Multisus 2 software.

${ }_{10}$ Calibrations

PB calibration curve were prepared by dissolving $\mathrm{FeCl}_{3}, 6 \mathrm{H}_{2} \mathrm{O}$ solutions from 0 to $30 \mu \mathrm{g}_{\mathrm{Fe}} / \mathrm{mL}$. These solutions were then diluted 2 times in $\mathrm{HCl} 6 \mathrm{M}$ and $50 \mu \mathrm{L}$ of that was mixed in triplicate with $50 \mu \mathrm{L}$ of $5 \%$ ferrocyanide solution in well. After 15 minutes 15 shaking and 1 minute of sonication, the absorbance at $690 \mathrm{~nm}$ was then measured and plotted (in arbitrary units: a.u.) as a function of iron concentration $\left(\mu \mathrm{g}_{\mathrm{Fe}} / \mathrm{mL}\right)$.

For ICP calibrations, standard iron $\left(\mathrm{Fe}^{3+}\right)$ solution was diluted in ultra-pure water to solutions from 0 to $20 \mathrm{ppm}\left(\mu \mathrm{g}_{\mathrm{Fe}} / \mathrm{mL}\right)$ and 20 measured 3 times in ICP.

For MSM calibrations, and in order to understand the coating and media effects on magnetic response, 3 different calibrations curves of iron oxide suspensions were done. $850 \mu \mathrm{L}$ of nakedSPION in $\mathrm{HNO}_{3} 10 \mathrm{mM}$ or PVA-SPION in $\mathrm{HNO}_{3} 10 \mathrm{mM}$ or FBS 25 with iron concentrations from 0 to few hundreds $\mu g_{\mathrm{Fe}}$ were dropped in the $1 \mathrm{~mL} \mathrm{MS2G}$ cells and their magnetic susceptibilities were measured in the MS2G sensor against $850 \mu \mathrm{L}$ of the same liquid without nanoparticle. Then magnetic susceptibility (SI) as a function of iron mass $\left(\mu \mathrm{g}_{\mathrm{Fe}}\right)$ was plotted.

${ }_{30}$ For organs SPION titrations with MSM, calibration curves were done by adding several volumes of PVA-SPION to a known mass of dry powder of a liver or a dry spleen stored in a $10 \mathrm{~mL}$ cell of MS2B sensor. Because the number of rat organs was not sufficient to prepare several calibrations standards, after each 35 PVA-SPION volume addition, the magnetic susceptibility was measured against a MS2B cell control organ (in dry powder for liver and dry for spleen). This operation was repeated from 0 to $6 \mathrm{mg}$ of iron for liver and from 0 to $0.3 \mathrm{mg}$ of iron for spleen. For comparison, SPION in suspensions from 0 to $5 \mathrm{mg}$ of iron were 40 diluted in $10 \mathrm{~mL}$ of $\mathrm{HNO}_{3} 10 \mathrm{mM}$ and their magnetic susceptibilities were measured. Organs or nanoparticles suspensions magnetic susceptibilities (SI) were plotted as a function of iron mass $\left(\mathrm{mg}_{\mathrm{Fe}}\right)$.

Samples preparation

${ }_{45}$ For PB and ICP measurements, $80 \mu \mathrm{L}$ of naked-SPION, PVASPION and sera injected with PVA-SPION were dissolved in $920 \mu \mathrm{L}$ of $\mathrm{HCl} 6 \mathrm{M}$ overnight at room temperature and diluted 6 times in water. Around $200 \mathrm{mg}$ of liver and between 100 to $200 \mathrm{mg}$ of spleen were dissolved in respectively 2 and $1 \mathrm{~mL}$ of 50 aqua regia overnight at room temperature, filtered at $0.45 \mu \mathrm{m}$ with cellulose syringe filter and diluted 12 times in water.

For magnetic susceptibility measurements, the SPION suspensions and dry organs were analyzed as such.

\section{Measurements of samples}

${ }_{55}$ For PB measurements, 3 times $25 \mu \mathrm{L}$ of the solutions of dissolved SPION suspensions or organs were dropped in wells of 96 wells plate. $25 \mu \mathrm{L}$ of $\mathrm{HCl} 6 \mathrm{M}$ and $50 \mu \mathrm{L}$ of $5 \%$ ferrocyanide solution were added in each well. The absorbance of each well was measured at $690 \mathrm{~nm}$ and the average of 3 absorbance 60 measurements led to the iron content of analyzed samples.

For ICP measurements, 3 times $1 \mathrm{~mL}$ of the solutions of dissolved SPION suspensions or organs were analyzed 3 times each in ICP. The average of the 3 measurements gave the iron content of analyzed samples.

65 For MSM measurements, $0.85 \mathrm{~mL}$ of SPION suspensions without any further modification were put in the $1 \mathrm{~mL} \mathrm{MS2G}$ cell and measured against the liquid used for the dilution of the SPION $\left(\mathrm{HNO}_{3} 10 \mathrm{mM}\right.$ for naked-SPION and PVA-SPION and FBS for PVA-SPION). For the organs measurements, a measured mass of 70 powder of liver or spleen was added in the $10 \mathrm{~mL} \mathrm{MS2B}$ cell and measured against a control dry liver or spleen in a $10 \mathrm{~mL} \mathrm{MS2B}$ cell. Their magnetic susceptibilities (in SI) were measured 3 times for 1 second and their average gave the iron content of analyzed samples.

75 The averages of the 3 iron concentrations in suspension were plotted for PB, ICP and MSM measurements with standard deviation errors. For organs iron content, the 9 results were shown separately because of the incertitude of in vivo biodistribution with standard deviation for the 3 measurements 80 per sample.

Comparison of magnetic susceptibility measurements of wet, dry and dry powder of livers and feasibility study on other organs

The magnetic susceptibilities of three whole livers with injected ${ }_{85}$ SPION (already measured following the protocol of dry powder described before) in 2 different other states: as such (wet) and dry; were measured 3 times of $1 \mathrm{~s}$ in the $10 \mathrm{~mL} \mathrm{MS} 2 \mathrm{~B}$ cell against a control whole liver in the same states were compared.

3 rats injected 15 minutes with $7 \mathrm{mg}$ PVA-SPION were 90 sacrificed. Different organs (liver, spleen, kidneys, lungs, bladder + urine, heart, brain, stomach and intestines) were analysed as such in magnetic susceptibility (MS2B cell) to measure their PVA-SPION biodistribution using the organ MSM calibration curve. The whole blood PVA-SPION content was also analysed 95 (MS2G cell) using the serum MSM calibration curve.

Detection limit of Magnetic Susceptibility method

Naked-SPION suspension was diluted in $\mathrm{HNO}_{3} 10 \mathrm{mM}$ from 0 to $7.8 \mu \mathrm{g}_{\mathrm{Fe}} / \mathrm{mL} .850 \mu \mathrm{L}$ of each suspension were dropped in the $1 \mathrm{~mL} \mathrm{MS2G}$ cells and their magnetic susceptibilities were 100 measured 3 times in the MS2G sensor against $850 \mu \mathrm{L}$ of $\mathrm{HNO}_{3}$ $10 \mathrm{mM}$. The standard deviations and the percentages of the standard deviations divided by the magnetic susceptibility value was also calculated to get estimate the precision of the measurement.

\section{${ }_{105}$ Results and discussion SPION characterizations}

The SPION have a maghemite phase $\left(\gamma-\mathrm{Fe}_{2} \mathrm{O}_{3}\right)$ with a mean crystallite's diameter of $7 \mathrm{~nm}$ (Table 1). Their hydrodynamic diameters are between $14 \mathrm{~nm}$ for the naked one and $25 \mathrm{~nm}$ when 110 they are coated with PVA. The naked SPION have no charge at physiological $\mathrm{pH}$, requiring a coating of PVA which provide a Zeta potential of $+20 \mathrm{mV}$. The mass ratio of $\mathrm{PVA} / \mathrm{Fe}$ found by TGA is as excepted equal to 9 . 


\section{Cite this: DOI: 10.1039/c0xx00000x}

\section{www.rsc.org/xxxxxx}

ARTICLE TYPE
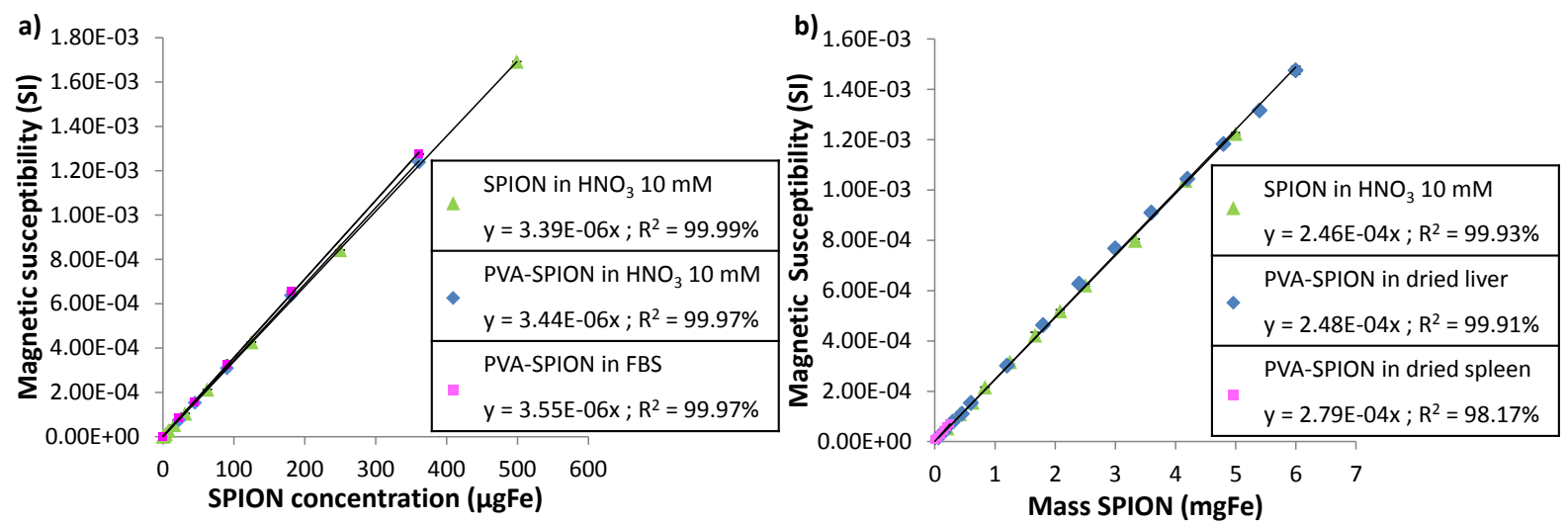

Fig. 1. a) Calibration curves of magnetic susceptibilities measurements (in SI) as a function of iron concentration. Measurements done with SPION in water and with PVA-SPION in water and foetal bovine serum (FBS) on the MS2G susceptometer sensor (1 mL cell); b) Calibration curves for magnetic susceptibilities measurements (SI) as a function of iron concentration. Measurements done with PVA-SPION in water, in powder of rat's dry liver and in 5 rat's dry spleen on the MS2B susceptometer sensor (10 mL cell)

Table 1.Physico-chemical characterizations of naked and PVA coated SPION

\begin{tabular}{ccccc} 
Particles & $\begin{array}{c}\text { TEM size } \\
(\mathbf{n m})\end{array}$ & $\begin{array}{c}\text { PCS size } \\
(\mathbf{n m})\end{array}$ & $\begin{array}{c}\text { Zeta potential } \\
(\mathbf{m V})\end{array}$ & $\begin{array}{c}\mathbf{P V A} / \mathbf{F e} \text { ratio } \\
\left(\mathbf{m g}_{\mathbf{P V A}} / \mathbf{m g}_{\mathrm{Fe}}\right)\end{array}$ \\
\hline Naked SPION & $7.2 \pm 2.5$ & $14 \pm 2$ & $\approx 0$ & 0 \\
\hline PVA-SPION & $7.2 \pm 2.5$ & $25 \pm 3$ & $+20 \pm 2$ & 9 \\
\hline \multicolumn{5}{c}{ TEM size: crystallite's mean diameter obtained by TEM micrographs } \\
analyses \\
\multicolumn{5}{c}{ PCS size: number weighted hydrodynamic diameter } \\
\hline
\end{tabular}

\section{Calibrations results}

The Magnetic susceptibility (SI) as a function of iron mass $\left(\mu \mathrm{g}_{\mathrm{Fe}}\right)$ 10 is plotted in the Fig. 1-a (triangles for SPION in water, diamonds for PVA-SPION in water and squares for PVA-SPION in FBS). The Magnetic susceptibility (SI) as a function of iron mass $\left(\mathrm{mg}_{\mathrm{Fe}}\right)$ is plotted for liver, spleen and nitric acid $10 \mathrm{mM}$ (respectively diamond, square and triangle lines in Fig. 1-b).

${ }_{15}$ For the three first calibration curves shown, the $\mathrm{R}^{2}$ coefficients of determination are higher than $99.9 \%$ which prove that the MSM are able to measure concentration of SPION in different media in a linear proportional way in the range of analyses as expected for $\mathrm{Fe}_{2} \mathrm{O}_{3}$ and as shown by McCloskey et al ${ }^{36}$. Moreover, the three 20 slope coefficients have approximately the same values; from 3.39 to $3.55 \cdot 10^{-6} \mathrm{SI} /\left(\mu \mathrm{g}_{\mathrm{Fe}}\right)$ with a standard deviation lower than $2.5 \%$; proving no significant influence of the coating and medium in magnetic response of SPION. For the calibration curves measured in water and dry liver in powder, the $\mathrm{R}^{2}$ coefficients of 25 determination are higher than $99.9 \%$ and higher than $98 \%$ for dry spleen in powder proving again that the MSM can measure SPION in dry organ in a same linear way as SPION in water. the three slope coefficients have approximately the same values; from 2.46 to $2.79 \cdot 10^{-4} \mathrm{SI} /\left(\mathrm{mg}_{\mathrm{Fe}}\right)$ with a standard deviation lower 30 than $7 \%$; proving that there is no significant influence of the matrix (either dry organ or water) in the magnetic susceptibility measurements of SPION. The differences observed between the 2 curves with SPION in water and in powder of dry liver and the calibration curve of dry spleen could be explained by the lower 35 mass of spleen in the MS2B $10 \mathrm{~mL}$ cell. In this last case, the SPION were only added at the bottom of the cell and the precision of the calibration curve was so lower than the other two which was proven by the lowest coefficients of determination at $98 \%$ instead of $99.9 \%$ for the other curves. However this 40 coefficient of determination is still acceptable since the measurements are linear and directly proportional and the SPION are detectable in small organs.

It is worth noting that with our protocol of MSM calibration, the samples of sera and of dry organs were not destroyed by 45 dissolving them as in PB and ICP methods. Then magnetic susceptibility calibration measurements are linearly proportional with a $\mathrm{R}^{2}$ coefficient higher than $99.9 \%$. It is also possible to detect SPION magnetic response with magnetic susceptibility measurements. Moreover, regarding the magnetic susceptibility 50 values, the background does not interfere with the measurements. We also found that water and serum without SPION magnetic susceptibilities measurements are between -1 to $0 \cdot 10^{-5}$ SI in accordance with the literature $\mathrm{e}^{30,37,38}$. The values measured from dried organs are in the same range of $1 \cdot 10^{-5}$ SI. These 55 observations are correlated by the calibration curves measurements where no influence of the media on the SPION magnetic susceptibility slopes was observed. Furthermore, the coating of the SPION does not seem to affect the MSM either. In this case it is possible to set calibration curves for organs 60 biodistribution measurements with only water, thus decreasing the number of control animals. Finally, it is important to notice that the slopes are different regarding the magneto-susceptometer used. The magnetic susceptibility measurement is linked to the frequency of analysis and these two instruments don't use the ${ }_{65}$ same frequency. Therefore it is necessary to conduct calibrations 
curves in the same susceptometer where the samples will be analysed.

\section{Measurements results}

Magnetic susceptibilities of SPION in SI units were measured in 5 suspensions in $10 \mathrm{mM} \mathrm{HNO}_{3}$, in foetal bovine serum and in rat's spleens and livers and gave iron content by using the calibrations curves previously performed. The samples were measured as such and then prepared (dissolved in $\mathrm{HCl} 6 \mathrm{M}$ or aqua regia) for PB and ICP analyses as explained before. The SPION contents 10 measured with these 3 methods were then compared. First SPION were quantified in a suspension with the 3 methods, either in $10 \mathrm{mM} \mathrm{HNO}_{3}$ or in foetal bovine serum (Fig. 2).

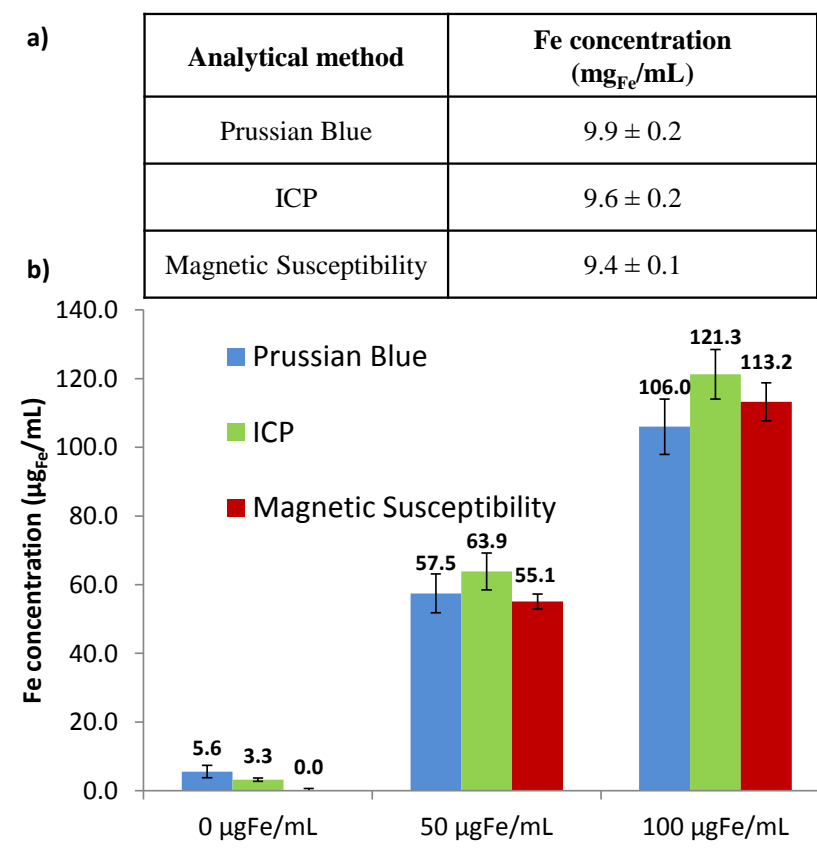

Fig. 2. a) Quantification of SPION in $\mathrm{HNO}_{3} 10 \mathrm{mM}$. Measurements done 15 with Prussian blue, ICP and magnetic susceptibility methods (MS2G susceptometer with $1 \mathrm{~mL}$ cell) b) quantification of PVA-SPION in foetal bovine serum. Measurements done with Prussian blue, ICP and magnetic susceptibility methods (MS2G susceptometer with $1 \mathrm{~mL}$ cell) and compared to estimated concentrations written below $(0,50$ and 100

20 $\left.\mu \mathrm{g}_{\mathrm{Fe}} / \mathrm{mL}\right)$

The initial observation from Fig. 2 is that the three methods are able to detect and quantify SPION concentrations in comparable values. Also, the medium (either nitric acid or serum) does not affect the measurements of the SPION titration.

${ }_{25}$ In sera analyses (Fig. 2-b), the SPION concentration is slightly higher than the 50 and $100 \mu \mathrm{g}_{\mathrm{Fe}} / \mathrm{mL}$ expected. This difference was observed in the three methods and thus is assumed to come from incertitude of SPION sampling with sera preparations.

However some iron is detected with PB and ICP methods on 30 control sera when no iron was detected with magnetic susceptibility. This shows that MSM is only sensitive to the superparamagnetic or ferromagnetic iron from iron nanoparticles and is not affected by the endogenous iron that was detected by the two optical in the range of 3 to $5 \mu \mathrm{g}_{\mathrm{Fe}} / \mathrm{mL}$.
${ }_{35}$ Biodistribution results of SPION in dry spleen and dry liver powder were measured with PB, ICP and MSM methods and are plotted respectively in Fig. 3 for comparison.

The three methods were able to determine the iron content in the two organs even with low contents in the spleen (from 0.05 to ${ }_{40} 0.6 \mathrm{mg}_{\mathrm{Fe}}$ ). The tendencies of the values are quite comparable for the three methods. For example, when the MSM value of liver 1 is around $4 \mathrm{mg}_{\mathrm{Fe}}$ the PB and ICP values were approximately 5 to $5.2 \mathrm{mg}_{\mathrm{Fe}}$ and when the MSM value is around $2 \mathrm{mg}_{\mathrm{Fe}}$ in liver 8 , the PB and ICP values were approximately $3 \mathrm{mg}_{\mathrm{Fe}}$. However, in 45 the two organs biodistribution measurements, the iron content values measured in injected rats are always slightly higher with PB and ICP than with MSM. The average difference between MSM values and PB and ICP values are respectively around $0.1 \mathrm{mg}_{\mathrm{Fe}}$ for the 8 injected spleens and $1.1 \mathrm{mg}_{\mathrm{Fe}}$ for the 8 injected 50 livers. Moreover, these two optical methods detected endogenous iron in control organs when the MSM did not. This background iron is present in a quite high proportion for these two organs with an average of $0.1 \mathrm{mg}_{\mathrm{Fe}}$ for the 4 control spleens and $1.1 \mathrm{mg}_{\mathrm{Fe}}$ for the 4 control livers. The background iron value is found in the 5512 rat's organs analysed proving that it is endogenous iron from spleens and livers. However these endogenous iron values measured in PB and ICP seems to vary significantly between the animal: from 0.004 to $0.16 \mathrm{mg}_{\mathrm{Fe}}$ for spleens (1 to 4 times differences) and 0.5 to $1.5 \mathrm{mg}_{\mathrm{Fe}}$ for livers (1 to 3 times

${ }_{60}$ differences). For that reason and in order to get an accurate average quantification of the iron value of an injected organ, many control animals would be needed. Therefore another advantage of MSM is that it can measure only the iron present as nanoparticles and allowing accurate biodistribution values of 65 magnetic nanoparticles not influenced by the endogenous iron of the organs eliminating the need for a large group of control samples.

Influence of the state of the organ on magnetic susceptibility measurements and feasibility study on other organs

${ }_{70}$ For this comparative study, organs had to be dried and crushed into powder before they were dissolved $t$ in aqua regia and then analysed by PB and ICP. To mimic the state of the organs analyzed by these two methods, magnetic susceptibility was measured on organ powder. In the first results obtained from 75 calibration or from SPION titration, the environment of SPION should not have any influence on the magnetic response. On this hypothesis, three livers from previous measurements (number 6 to 8), were previously measured in MSM in wet and dry form and compared to the values obtained in dry powder from Fig. 4.

80 The magnetic susceptibility responses are not affected by the state of the organ is. With this observation, MSM biodistribution measurements could be measured on whole organs without any modifications or preparatory steps.

To support these results, different wet organs of rats injected with ${ }_{85} 7 \mathrm{mg}_{\mathrm{Fe}}$ PVA-SPION $15 \mathrm{~min}$ prior to being sacrificed were passed on MSM instruments. Using appropriate calibration curves, their amount of PVA-SPION (in mg/organ) were obtained (Table 2). 

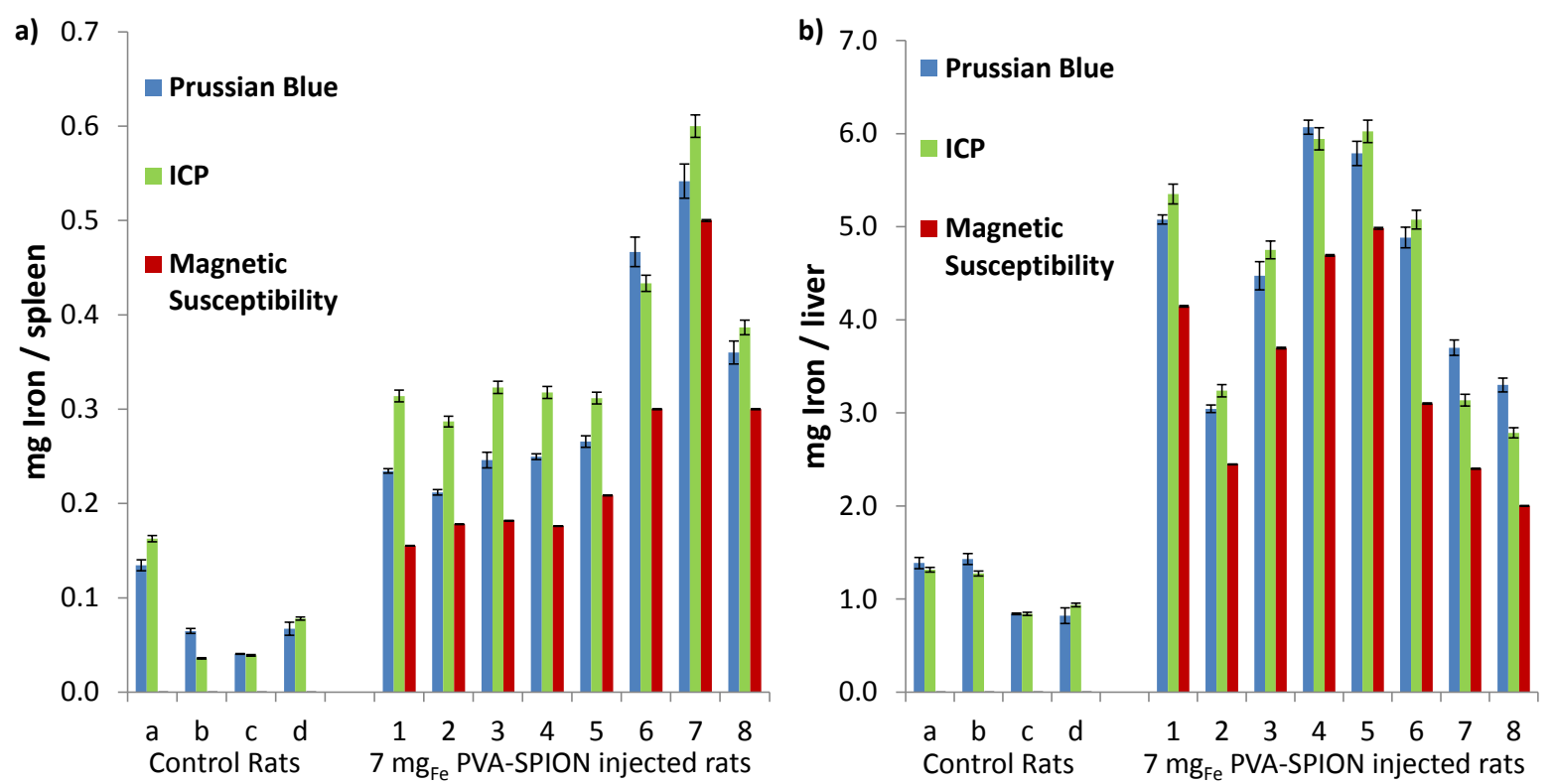

Fig. 3. a) Biodistribution of iron in dry spleens. Measurements done using Prussian blue, ICP and magnetic susceptibility methods (MS2B susceptometer with $10 \mathrm{~mL}$ cell). a to d: 4 control rats (without any SPION injected) and 1 to 8: 8 rats injected with $7 \mathrm{mgFe}$ of PVA-SPION 15 minutes after injection ; b) Biodistribution of iron in dry livers. Measurements done with Prussian blue, ICP and magnetic susceptibility methods (MS2B susceptometer with $10 \mathrm{~mL}$ cell). a to d: 4 control rats (without any SPION injected) and 1 to $8: 8$ rats injected with $7 \mathrm{mg}_{\mathrm{Fe}}$ of PVA-SPION 15 minutes after injection

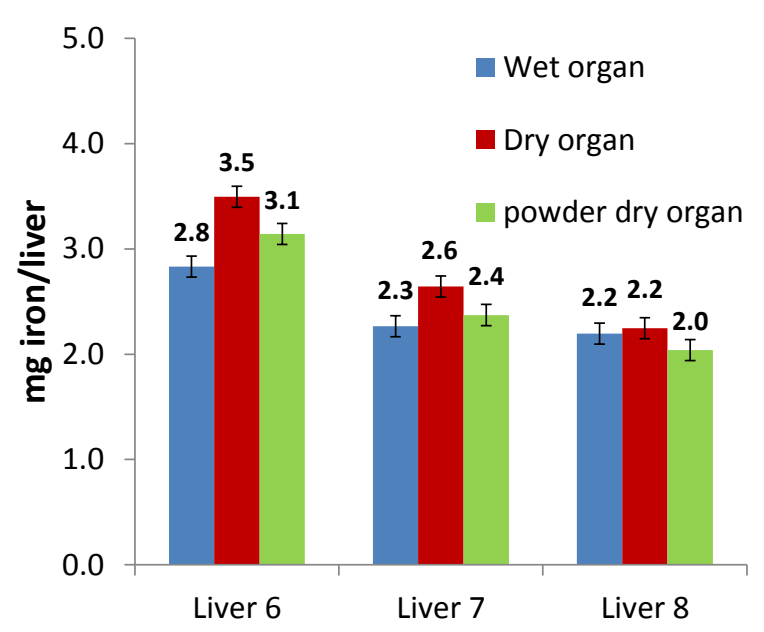

Fig. 4. Comparison of SPION quantification as a function of the state of the liver. Livers (livers 6 to 8 of Fig. 3-b) in different states (wet, dry and dry powder) from rats injected with $7 \mathrm{mg}_{\mathrm{Fe}}$ of PVA-SPION for 15 minutes were measured with magnetic susceptibility method (MS2B susceptometer with $10 \mathrm{~mL}$ cell).

Of the $7 \mathrm{mg}_{\mathrm{Fe}}$ PVA-SPION injected, around $6.6 \mathrm{mg}_{\mathrm{Fe}}$ were detected mainly in liver and blood (respectively 3.2 and $\left.3.0 \mathrm{mg}_{\mathrm{Fe}}\right)$. A little amount of PVA-SPION was found in spleen, 15 approximately the same amount measured previously (Fig. 3). This shows that it is possible to measure magnetic particles biodistribution in all organs including blood. This confirms further that MSM is suitable for biodistribution measurements in the same range of analysis.
20 Table 2 SPION biodistribution measured by magnetic susceptibility method on different wet organs of rats injected $15 \mathrm{~min}$ with $7 \mathrm{mg}$ PVA-SPION

\begin{tabular}{cc|cc} 
Organ & mg iron / organ & Organ & mg iron / organ \\
\hline Blood & $3.2 \pm 0.7$ & Bladder & $0.0 \pm 0.0$ \\
Liver & $3.0 \pm 0.4$ & Heart & $0.1 \pm 0.0$ \\
Spleen & $0.2 \pm 0.0$ & Brain & $0.0 \pm 0.0$ \\
Kidney & $0.0 \pm 0.0$ & Stomach & $0.0 \pm 0.0$ \\
Lung & $0.0 \pm 0.0$ & Intestine & $0.1 \pm 0.1$ \\
\hline \multicolumn{2}{c}{ Total } & \multicolumn{2}{|c}{$\mathbf{6 . 6 \pm 0 . 6}$}
\end{tabular}

\section{Detection limit of magnetic susceptibility method}

As shown by Guo et $a l .{ }^{30}$ and provided by the manufacturer the 25 minimal detection of the magneto-susceptometer is $\left(2 \cdot 10^{-6} \mathrm{SI}^{35}\right)$, this minimal detection value for SPION was estimated by measuring magnetic susceptibilities of SPION in concentrations around the ppm $\left(\mu \mathrm{g}_{\mathrm{Fe}} / \mathrm{mL}\right)$ scale (Table 3$)$.

At 0 and $0.6 \mu \mathrm{g}_{\mathrm{Fe}} / \mathrm{mL}$, the standard deviation is high and the ${ }_{30}$ MSM values are lower than the precision of the instrument $\left(2 \cdot 10^{-6} \mathrm{SI}\right)$. For 1.0 and $1.9 \mu \mathrm{g}_{\mathrm{Fe}} / \mathrm{mL}$, the magnetic susceptibility is respectively at 5 and $6 \cdot 10^{-6} \mathrm{SI}$, values higher than the theoretical precision of the instrument. However these two values are not proportional to the high error for $1.0 \mu \mathrm{g}_{\mathrm{Fe}} / \mathrm{mL}$. However, ${ }_{35}$ for 1.9 and $3.8 \mu \mathrm{g}_{\mathrm{Fe}} / \mathrm{mL}$, the standard deviations are around 5 to $6 \%$ and the MSM values are proportional (when the concentration is doubled the MSM value is also doubled) which should prove that at these concentrations, the instrument is able to detect SPION with an error of $5 \%$. Two $\mu \mathrm{g}_{\mathrm{Fe}} / \mathrm{mL}(2 \mathrm{ppm})$ is 
likely the detection limit of MSM.

Table 3. Magnetic susceptibility values (in SI) for several SPION concentrations (in $\mu \mathrm{g}_{\mathrm{Fe}} / \mathrm{mL}$ ). The standard deviations and the percentage of the standard deviation divided by the magnetic susceptibility value is 5 also given. The measurements were done on the MS2G susceptometer sensor (1 mL cell).

\begin{tabular}{cccc}
\hline $\begin{array}{c}\text { SPION } \\
\text { concentration } \\
\left(\mu \mathrm{g}_{\mathrm{Fe}} / \mathrm{mL}\right)\end{array}$ & $\begin{array}{c}\text { Magnetic } \\
\text { susceptibility (SI) }\end{array}$ & $\begin{array}{c}\text { Standard } \\
\text { deviation (SI) }\end{array}$ & $\%$ difference \\
\hline 7.8 & $2.71 \cdot 10^{-6}$ & $1.19 \cdot 10^{-8}$ & $0 \%$ \\
3.9 & $1.32 \cdot 10^{-5}$ & $6.41 \cdot 10^{-7}$ & $5 \%$ \\
1.9 & $6.39 \cdot 10^{-6}$ & $3.85 \cdot 10^{-7}$ & $6 \%$ \\
\hline 1.0 & $5.09 \cdot 10^{-6}$ & $1.00 \cdot 10^{-6}$ & $20 \%$ \\
0.6 & $0.92 \cdot 10^{-6}$ & $3.77 \cdot 10^{-7}$ & $41 \%$ \\
0 & $0.66 \cdot 10^{-6}$ & $6.41 \cdot 10^{-7}$ & $97 \%$ \\
\hline
\end{tabular}

\section{Conclusions}

In this study, it was established that magnetic susceptibility measurement is a better alternative to ICP or optical methods for 10 the quantification of magnetic nanoparticles and their biodistribution either in organs or in biological fluids without any influence of the media and of the coating of the SPION. We have thoroughly explained the method to set up calibration curves to obtain iron concentration from magnetic susceptibility and 15 proven that this method was linearly proportional $\left(\mathrm{R}^{2}>99.9 \%\right)$. The iron quantification trends obtained with MSM were comparable to ICP or PB measurements in suspension or in organs biodistribution even at low SPION concentrations such as $50 \mu \mathrm{g}_{\mathrm{Fe}} / \mathrm{mL}$ in sera or less than $0.2 \mathrm{mg}_{\mathrm{Fe}}$ in organs.

${ }_{20}$ One of the most important advantages of this method is the absence of endogenous iron measurement bias which is present in both ICP and PB methods. It was shown that the difference of background iron content, between 2 control organs could be quite significant (3 to 4 times) requiring a lot of control organs to get 25 an accurate measurement of the endogenous iron value. When only biodistribution and quantification of magnetic particles are needed, magnetic susceptibility seems to be more valid and accurate than other techniques because no control animals are required. In fact, it was proven during this study that MSM values 30 are only influenced by the iron from magnetic particles and not by free iron in solution.

Regarding the preparation of samples, digestion of organs or suspensions for PB and ICP usually takes 24 hours. With MSM, the measurements can be done as soon as the samples are 35 collected since the magneto-susceptometer is portative ${ }^{23,24}$. After appropriate preparation of calibration curve, the sample measurement takes only 5 seconds resulting in an accurate and reproducible quantification. While measuring control samples is recommended, it is not necessary as it was demonstrated during 40 that work. Since the magnetic susceptibility value of bared samples was found to be approximately 0 for most samples including: water, $\mathrm{HNO}_{3} 10 \mathrm{mM}$, FBS, wet, dry or dry powder organs. The samples analysed in MSM did not need any modification because the background (either media, coating of 45 particles or state of organ) did not affect the magnetic response. Moreover, the samples are not destroyed and could be kept for further analysis. The only recommendation with this method would be to use the same magnetic particles for the calibration and the experiments; magnetic susceptibility being sensitive to 50 the size of the magnetic core ${ }^{39}$.

Magnetic susceptibility method precision is around $2 \mathrm{ppm}$ $\left(2 \mu \mathrm{g}_{\mathrm{Fe}} / \mathrm{mL}\right)$, value higher than ICP method which is around 0.1 ppm $\left(0.1 \mu \mathrm{g}_{\mathrm{Fe}} / \mathrm{mL}\right)$. However with MSM, the samples are not diluted and can be measured as such whereas they have to be 55 dissolved and diluted for PB or ICP methods. In this case the precision of ICP and MSM could be considered as comparable. Comparison and advantages of MSM technique are described in Table 4.

Table 4. Summary of difference between PB and ICP methods compared 60 to MSM technique

\begin{tabular}{cccc}
\hline & PB & ICP & MSM \\
\hline Digestion of samples & Yes & Yes & No \\
Can sample be re-analyzed & No & No & Yes \\
Sensitive to endogenous iron & Yes & Yes & No \\
Control samples needed & Yes & Yes & No \\
Minimal detection (ppm) & 2 & 0.1 & 2 \\
$\begin{array}{c}\text { Minimal dilution } \\
\text { Minimal detection with dilution } \\
(\mathrm{ppm})\end{array}$ & $6 \mathrm{X}$ & $6 \mathrm{X}$ & No \\
\hline
\end{tabular}

PB: Prussian Blue; ICP: Induced Coupled Plasma spectroscopy; MSM: Magnetic Susceptibility Measurements

\section{Acknowledgments}

This work has been supported by the NanoDiaRA project, grant 65 agreement number 228929, funded by the EC Seventh Framework Program FP7-NMP-2008-L

\section{References}

1. D. L. Huber, Small, 2005, 1, 482-501.

2. A. K. Gupta and M. Gupta, Biomaterials, 2005, 26, 3995-4021.

70 3. G. Wang and X. Su, Analyst, 2011, 136, 1783-1798.

4. L. Maurizi, H. Bisht, F. Bouyer, and N. Millot, Langmuir, 2009, 25, 8857-8859.

5. B. Basly, G. Popa, S. Fleutot, B. P. Pichon, A. Garofalo, C. Ghobril, C. Billotey, A. Berniard, P. Bonazza, H. Martinez, D. Felder-Flesch, and S. Begin-Colin, Dalton Trans., 2013, 42, 2146-2157.

6. J. Yang, J. Gunn, S. R. Dave, M. Zhang, Y. A. Wang, and X. Gao, Analyst, 2008, 133, 154-160.

7. T. K. Jain, M. K. Reddy, M. A. Morales, D. L. Leslie-Pelecky, and V. Labhasetwar, Molecular Pharmaceutics, 2008, 5, 316-327.

80 8. S. H. Crayton, D. R. Elias, A. Al Zaki, Z. Cheng, and A. Tsourkas, Biomaterials, 2012, 33, 1509-1519.

9. L. Bromberg, S. Raduyk, and T. A. Hatton, Analytical Chemistry, 2009, 81, 5637-5645.

10. V. Plassat, M. S. Martina, G. Barratt, C. Menager, and S. Lesieur, 85 International Journal of Pharmaceutics, 2007, 344, 118-127.

11. M. J.-E. Lee, O. Veiseh, N. Bhattarai, C. Sun, S. J. Hansen, S. Ditzler, S. Knoblaugh, D. Lee, R. Ellenbogen, M. Zhang, and J. M. Olson, Plos One, 2010, 5.

12. Y.-K. Chang, Y.-P. Liu, J. H. Ho, S.-C. Hsu, and O. K. Lee, Journal of Orthopaedic Research, 2012, 30, 1499-1506.

13. K. Basavaiah, U. Chandrashekar, and H. C. Prameela, Farmaco (Societa chimica italiana : 1989), 2003, 58, 141-8. 
14. S. Boutry, D. Forge, C. Burtea, I. Mahieu, O. Murariu, S. Laurent, L. V. Elst, and R. N. Muller, Contrast Media Mol. Imaging, 2009, 4, 299-304.

15. E. R. Dadashzadeh, M. Hobson, L. H. Bryant, D. D. Dean, and J. A. Frank, Contrast Media Mol. Imaging, 2013, 8, 50-56.

16. A. J. Cole, A. E. David, J. Wang, C. J. Galban, H. L. Hill, and V. C. Yang, Biomaterials, 2011, 32, 2183-2193.

17. D. Beauchemin, Analytical Chemistry, 2006, 78, 4111-4136.

18. J. Zhuang, K. Fan, L. Gao, D. Lu, J. Feng, D. Yang, N. Gu, Y.

10 Zhang, M. Liang, and X. Yan, Molecular Pharmaceutics, 2012, 9, 1983-1989.

19. A. Ruiz, Y. Hernández, C. Cabal, E. González, S. VeintemillasVerdaguer, E. Martínez, and M. P. Morales, Nanoscale, 2013.

20. J. Corchero and A. Villaverde, Trends in Biotechnology, 2009, 27, 468-476.

21. J. B. Mandeville, J. Moore, D. A. Chesler, L. Garrido, R. Weissleder, and R. M. Weisskoff, Magnetic Resonance in Medicine, 1997, 37, $885-890$.

22. B. E. Van Beers, C. Sempoux, R. Materne, M. Delos, and A. M. Smith, Journal of Magnetic Resonance Imaging, 2001, 13, 594-599.

23. V. Hoffmann, M. Knab, and E. Appel, Journal of Geochemical Exploration, 1999, 66, 313-326.

24. T. Boyko, R. Scholger, H. Stanjek, and M. Team, Journal of Applied Geophysics, 2004, 55, 249-259.

25 25. L. N. Mulay and I. L. Mulay, Analytical Chemistry, 1978, 50, 274R282R.

26. L. Gutierrez, R. Mejias, D. F. Barber, S. Veintemillas-Verdaguer, C. J. Serna, F. J. Lazaro, and M. P. Morales, Journal of Physics DApplied Physics, 2011, 44.

30 27. B. Chertok, A. J. Cole, A. E. David, and V. C. Yang, Molecular Pharmaceutics, 2010, 7, 375-385.

28. V. Strom, K. Hultenby, C. Gruttner, J. Teller, B. Xu, and J. Holgersson, Nanotechnology, 2004, 15, 457-466.

29. X. Jin, J. J. Chalmers, and M. Zborowski, Analytical Chemistry, $35 \quad 2012,84,4520-4526$.

30. H. Guo, Y. Wyart, J. Perot, F. Nauleau, and P. Moulin, Journal of Membrane Science, 2010, 350, 172-179.

31. M. Chastellain, A. Petri, and H. Hofmann, in Quantum Dots, Nanoparticles and Nanowires, ed. P. M. H. W. Z. L. GuyotSionnest, 2004, vol. 789, pp. 269-272.

32. R. Massart, E. Dubois, V. Cabuil, and E. Hasmonay, J. Magn. Magn. Mater., 1995, 149, 1-5.

33. A. Chastellain, A. Petri, and H. Hofmann, Journal of Colloid and Interface Science, 2004, 278, 353-360.

45 34. B. Steitz, J. Salaklang, A. Finka, C. O’Neil, H. Hofmann, and A. Petri-Fink, Bioconjugate Chemistry, 2007, 18, 1684-1690.

35. J. Dearing, Using the Bartington MS2 system. Kenilworth, Chi Publ, 1994.

36. K. E. McCloskey, J. J. Chalmers, and M. Zborowski, Analytical Chemistry, 2003, 75, 6868-6874.

37. M. J. Azanza, B. H. Blott, A. Delmoral, and M. T. Peg, Bioelectrochemistry and Bioenergetics, 1993, 30, 43-53.

38. F. Shen, H. Hwang, Y. K. Hahn, and J.-K. Park, Analytical Chemistry, 2012, 84, 3075-3081.

55 39. B. Payet, D. Vincent, L. Delaunay, and G. Noyel, J. Magn. Magn. Mater., 1998, 186, 168-174.

1.

$\dagger$ Electronic Supplementary Information (ESI) available: [included at the end of the manuscript]. 